\title{
Contribuições da Geografia e do Sensoriamento Remoto como ferramenta auxiliar no planejamento espacial do Turismo, um estudo de caso sobre o Parque Nacional da Serra do Cipó-MG
}

\section{Contributions of Geography and Remote Sensing as an auxiliary tool in the planning space} tourism, a case study on the Serra do Cipó National Park MG

\author{
Erick Faria e Manuella Teixeira \\ Pontifícia Universidade Católica de Minas Gerais,MG, Brasil \\ erickolifaria@gmail.com \\ Universidade Federal de Minas Gerais, MG, Brasil \\ manuellabiagioni@gmail.com
}

\section{Resumo}

O presente estudo buscou mostrar de que maneira a geografia no uso do sensoriamento remoto como ferramenta para a análise espacial através de uma interpretação do espaço geográfico referente a sua organização, pode auxiliar o planejamento do turismo, uma vez que o mesmo utiliza o espaço para sua efetivação. Utilizando-se de dados gratuitamente disponibilizados e de softwares livres, em plataformas de mapeamento colaborativos e também de técnicas já conhecidas no sensoriamento remoto, buscou-se levantar informações importantes que sirvam de subsidios ao profissional que pretender planejar o turismo. Estas informações permitem ao profissional uma compreensão e interpretação dos aspectos que tangem a geografia socioespacial e os aspectos ambientais, econômicos e históricos, essenciais para a produção e prática de um modelo turístico eficaz. Como estudo de caso, no presente trabalho foi realizada uma atividade exploratória de campo, delimitando sua pesquisa no Parque Nacional da Serra do Cipó-MG e seu entorno.

Palavras-chave: Turismo; Sensoriamento Remoto; Serra do Cipó

\section{Abstract}

This study aimed to show how geography in the use of remote sensing as a tool for spatial analysis through an interpretation of the geographical area related to your organization, can assist the planning of tourism, since it uses the space for your effective. Using data freely available and free software in collaborative mapping platforms and also known techniques in remote sensing, we tried to get important information to serve as subsidies for professional who want to plan tourism. This information allows the professional understanding and interpretation of the aspects that concern the socio-geography and the environmental, economic and historical, essential for the production and practice of effective tourism model. As a case study, in this study an exploratory field of activity was carried out, defining their research in the Serra do Cipó National Park MG and its surroundings.

Keywords: Tourism; Remote sensing; Serra do Cipo 


\section{Introdução}

As geotecnologias vêm apresentando crescimento considerável nos últimos anos com o avanço tecnológico acessível a todos os públicos, deixando, assim, de ser algo exclusivamente dos geógrafos e cartógrafos, passando a ser acessível para todos os públicos. Com a popularização dos smartphones, aplicativos que utilizam o SIG estão sendo explorados por pessoas de todas as faixas etárias como apoio para o planejamento de viagens, auxílios de navegações rodoviárias entre outros.

O sensoriamento remoto como uma técnica da geografia, vem ao longo dos anos auxiliando na compreensão e na distribuição espacial dos dados e fenômenos que ocorrem no espaço. Devido a ampla disponibilidade de sistemas de informações geográficas (SIG) em softwares, plataformas web e aplicativos de smartphones de fácil manuseio e a custo acessível ou disponibilizados de maneira gratuita, é permitido que profissionais de outras áreas e, mesmo o público leigo, faça o uso desta técnica.

Desta maneira, uma aproximação das pessoas envolvidas com o turismo, sendo elas empresários, gestores e os próprios turistas, vem acontecendo entre estas plataformas. Estes aplicativos SIG's, com plataformas cujo objetivo é obter informações, e auxiliar o turista no que tange hospedagem e transporte, vêm se mostrando eficientes quando se leva em conta o número de indivíduos novos cadastrados nos aplicativos e a satisfação declarada pelos mesmos nas plataformas.

Alguns trabalhos como os de (RESENDE e XAVIER, 2008; STEINKE e SILVA, 2006; FREITAS, 2006) já sinalizaram a importância e a capacidade do SIG em auxiliar no planejamento e aprimoramento da atividade turística nos municípios e regiões brasileiras. Em um momento em que cada vez mais as informações georreferenciadas tornamse não somente públicas, mas, acessíveis a todos os públicos, o SIG aliado ao planejamento turístico torna-se uma ferramenta indispensável para o turismólogo.

Os modelos de turismo praticados no Brasil foram criticados por Freitas (2006), sendo classificados como: “incapazes de responder questões simples, sobre como e onde praticar e incentivar o turismo". Mesmo com o avanço das tecnologias e do incentivo do Estado para a melhoria de infraestrutura turística, há espaço para novos métodos e modelos que contemplem uma visão integrada do espaço social e espaço geográfico, sendo um deles o SIG.

Com o intuito de mostrar a potencialidade do SIG como ferramenta auxiliar ao planejamento do turismo, o presente estudo teve como objetivo analisar as informações disponíveis na região da Serra do Cipó (MG) - tratado neste trabalho como PARNA Cipó - e como as mesmas são de grande importância para o planejamento turístico.

\subsection{Local de estudo}

A Serra do Cipó se localiza na região central do estado de Minas Gerais, na porção sul da cadeia do Espinhaço. De acordo com o ICMBio, em setembro de 1984 foi criado o Parque Nacional da Serra do Cipó, estendendo-se entre os municípios de Jaboticatubas, Santana do Riacho, Morro do Pilar e Itambé do Mato Dentro. Com uma área total de 33.800 hectares, o Parque tem como principal objetivo preservar a riqueza natural nativa da região, proporcionando a visitação de forma ordenada. Para somar mais proteção a toda esta riqueza natural, em 1990 foi criada a Área de Proteção Ambiental - APA Morro da Pedreira. A mesma circunda toda a área do Parque Nacional da Serra do Cipó e, juntas, protegem uma área de mais de 100.000 hectares.

Com relação à vegetação, o território do Parque se encontra em uma região de transição entre Cerrado e Mata Atlântica. O mesmo se aplica à Área de Proteção Ambiental Morro da Pedreira. No que tange à hidrografia, nas porções 
norte e nordeste do Parque encontram-se as nascentes de vários córregos que formam os rios Preto (Morro do Pilar) e do Peixe (divisa entre Morro do Pilar e Itambé do Mato Dentro), importantes afluentes do Santo Antônio, que banha diversos municípios da bacia do rio Doce. Mais ao sul, em território da APA Morro da Pedreira, nascem os rios Entancado, Preto do Itambé (Itambé do Mato Dentro) e do Tanque (Itabira), todos também tributários do Santo Antônio, rio de importância estadual.

\section{Materiais e métodos}

Os materiais e métodos do presente trabalho se deram a partir de três etapas, sendo elas: a revisão bibliográfica acerca do tema do trabalho, a confecção dos mapas temáticos e, por último, a validação em campo no PARNA Cipó e em seu entorno. As etapas e procedimentos são detalhados a seguir:

\subsection{Revisão Bibliográfica}

Primeiramente, foi-se realizado um estudo acerca do sensoriamento remoto como ferramenta auxiliar ao planejamento do turismo. Os trabalhos em que se buscou referências metodológicas e conceituais foram os realizados por (RESENDE e XAVIER, 2008; STEINKE e SILVA, 2006; FREITAS, 2006). A revisão bibliografia serviu de base para a compreensão de aspectos relevantes ao tema, e como um "treinamento do olhar" do pesquisador antes das etapas posteriores, enfatizando as partes relevantes a abordar e quais informações são imprescindíveis de se levantar para a realização de um bom trabalho.

\subsection{Mapeamento dos pontos turísticos e de lazer}

O mapeamento das trilhas e pontos turísticos apresentados ao longo deste trabalho foram obtidos por meio da plataforma Open Street Map, com o auxílio do software QGIS versão 2.16.1.

As informações relativas ao relevo e hipsometria do local de estudo foram obtidas através do modelo digital de variáveis morfométricas com dados SRTM, utilizando-se da metodologia proposta por Valeriano (2007), para obtenção e visualização das informações. As imagens foram adquiridas junto ao programa Topodata do INPE.

Para a análise da cobertura vegetal foi utilizado o Índice de Vegetação da Diferença Normalizada (NVDI), proposto por Rouse et al (1973), com a finalidade de identificar os locais de vegetação densa, vegetação rasa ou rasteira e solo exposto na paisagem, uma vez que a razão entre bandas permite a descriminação de sutis comportamentos de diferentes alvos.

As imagens utilizadas para a composição do índice NDVI foram do satélite Landsat-8, obtidas junto ao INPE, pertencentes ao dia 17/08/2016, que através da junção das bandas 5 e 4 do sensor OLI (Operacional Land Imager), no software QGIS obteve-se a caracterização da vegetação do local. O índice NDVI expressa a diferença entre as bandas do infravermelho próximo e do vermelho normalizada através da soma de suas bandas. A relação para obtenção do índice NDVI é expressa na seguinte relação:

$$
\mathrm{NDVI}=\frac{\text { Banda } 5-\text { Banda } 4}{\text { Banda } 5+\text { Banda } 4}
$$




\subsection{Trabalho de campo}

Para validação dos mapeamentos efetuados na etapa anterior, foi realizado um trabalho de campo de caráter exploratório entre os dias 04 e 06 de março de 2016, na região do Parque Nacional da Serra do Cipó e seu entorno.

Foi realizada uma caminhada pelas trilhas do parque, no dia 04 saindo da portaria principal com destino a cachoeira da Farofa, onde buscou-se analisar, com o auxílio do GPS, a validação das informações obtidas no mapeamento da etapa anterior.

No dia 05 , foi feita uma visita a área de camping e cachoeira Véu da Noiva, local de intensa visitação e um dos principais destinos turísticos da região da Serra do Cipó. Posteriormente, foi percorrido o caminho conhecido como Trilha dos Escravos.

No dia 06 , foi realizada uma trilha passando por três atrativos, a cachoeira do Tomé, a cachoeira da Chica, e o Lageado, todas abastecidas pelo rio Cipó. Por fim, chegou-se à cachoeira Grande, também com o objetivo de validação do mapeamento realizado na etapa anterior.

\section{Sistemas de informação geográficas e sensoriamento remoto}

Com o avanço da tecnologia e a popularização do smartphone, o sensoriamento remoto deixou de ser exclusivamente uma ferramenta de geógrafos e profissionais da área e passou a ser algo do cotidiano das pessoas. O sensoriamento remoto e as novas geotecnologias, quem vêm surgindo a cada dia que se passa, têm se mostrado como grandes auxiliares nas tarefas do dia a dia das pessoas, uma vez que, de forma prática e acessível, as pessoas conseguem planejar as melhores rotas de destino para o trabalho, para um passeio, ou mesmo para se deslocar em lugares desconhecidos.

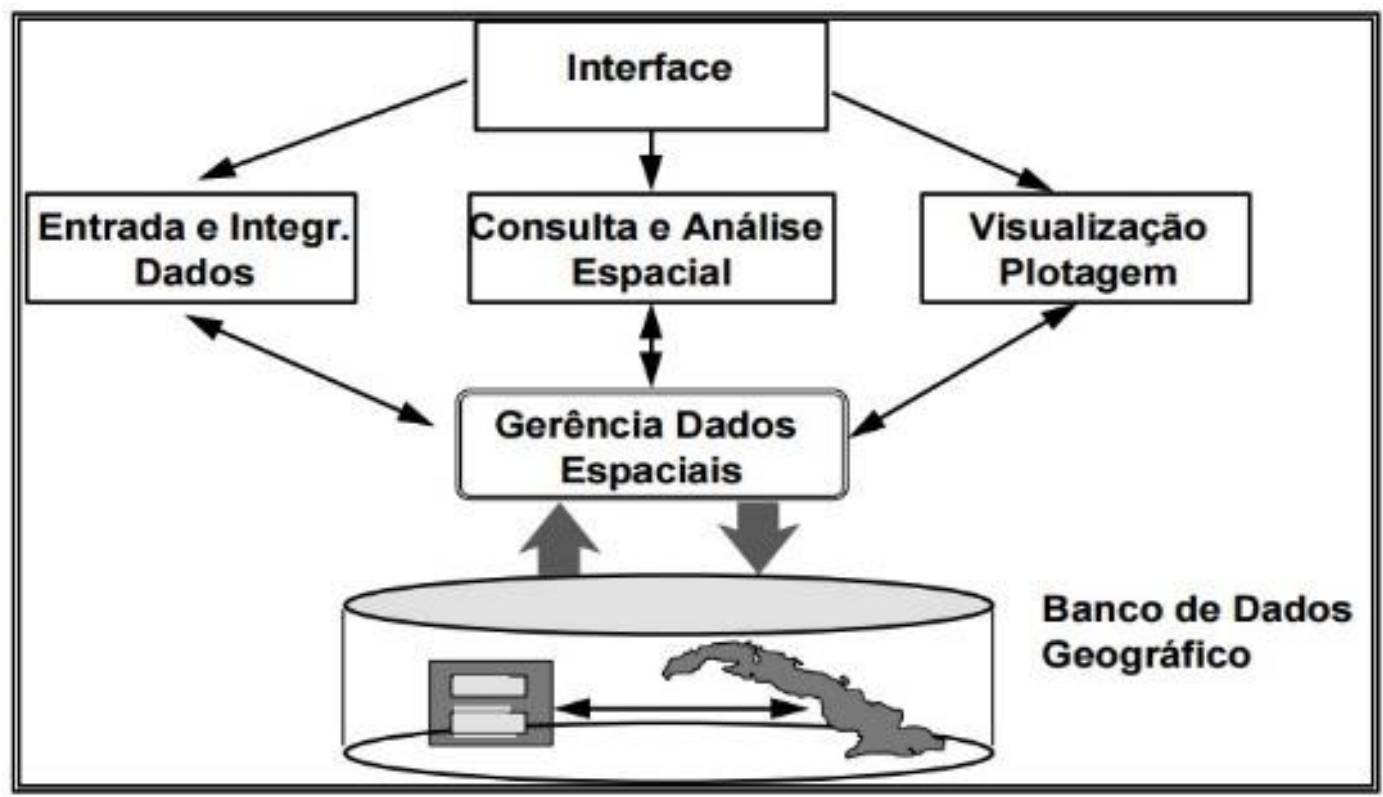

Figura 1 - Arquitetura de Sistema de Informações Geográficas. Fonte: Câmara et al. (2002)

A figura 1 é um esquema simplificado do modelo mais utilizado atualmente pelas plataformas e aplicativos para armazenamento das informações até sua disponibilidade com a interface gráfica do usuário (CÂMARA et al, 2002). Esta arquitetura permite que vários dados sejam armazenados em uma base de dados de informações georreferenciadas, para os mais diversos usos, inclusive para o turismo. 
Novos projetos de mapeamento colaborativo no qual usuários registrados e cadastrados podem mapear com relativa facilidade e sem conhecimentos prévios de sensoriamento remoto, colaboram para a construção de um banco de dados geográficos e alimentam esta estrutura SIG em uma velocidade surpreendente. Pensar uma base de dados, criada e mantida pelo governo através do Ministério do Turismo e órgãos de sua autarquia, que contemplem as informações referentes ao Sistema de Informações Geográficas voltadas para o turismo, não é algo difícil de ser feito. Plataformas que utilizam o mapeamento colaborativo, com recursos muito mais limitados do que o governo brasileiro conseguem fazer bons trabalhos e servem de grande ajuda para a população.

Um projeto de mapeamento colaborativo que vem mostrando crescimento nos últimos anos e se mostrando muito útil aos turistas, principalmente aqueles que praticam constantemente o Ecoturismo, é o projeto intitulado Open Street Map. De maneira simples e automática, esta plataforma permite que qualquer usuário se cadastre no site e colabore com seus conhecimentos mapeando os locais em que tem conhecimento, e contribuindo para um mapeamento mais preciso, inclusive de trilhas até então não mapeadas e não disponibilizadas em outras bases de dados. A plataforma Open Street Map permite que usuários que praticam o Ecoturismo e utilizam o GPS como auxiliar nas suas caminhadas, salvando o trajeto no aparelho, possam fazer o upload destas trilhas na plataforma e contribuir com o mapeamento de novas áreas de interesse da comunidade. Com este projeto de mapeamento colaborativo por aqueles que mais entendem a respeito dos melhores locais e melhores caminhos para a prática do Ecoturismo, os próprios usuários, cabe ao profissional turismólogo fazer uso desta plataforma a fim de planejar áreas de interesse para os praticantes do Ecoturismo.

Uma plataforma muito utilizada por praticantes de caminhada, ciclismo, vela, equitação, mergulho, parapente e, também, amantes de trilhas ecológicas, é representada pelo site e aplicativo de smartphone Wikiloc. Lançado em 2006, o site oferece que o usuário faça o upload a partir do seu aparelho GPS as trilhas percorridas e pontos de interesses aos demais membros. O Wikiloc permite a sobreposição de seus dados nas plataformas Open Street Map, o Open Cycle Map relacionada, USGS Imagery Topo Mapa e integração com o software Google Earth. O Wikiloc conta atualmente com 2.112.710 membros, explorando e partilhando 4.883.539 trilhas e 8.036.439 fotos ao ar livre ${ }^{1}$.

Vale lembrar também a respeito da plataforma mais utilizada atualmente, quando se diz respeito ao acervo de mapas e informações georrefenciadas de locais de interesse, o GoogleMaps, um produto da empresa Google Inc. Hoje o GoogleMaps, tanto na sua forma de aplicativo para smartphone, quanto sua versão como página de internet acessada por meio do desktop, é talvez a plataforma mais utilizada para o planejamento de rotas turísticas e informações geográficas (distância a ser percorrida entre os pontos de interesse, informações sobre o estabelecimento, fotos da frente do local, estimativa de tempo de viagem e informações sobre as rotas de deslocamento), para as pessoas que sequer conhecem a cidade ou local de destino.

Diante dessa perspectiva, o sensoriamento remoto e os SIG's vêm dando ao turista certa autonomia e segurança ao fornecer informações com considerável precisão, sem a necessidade de estar presente no local. O turista não mais precisa carregar papeis e/ou revistas com informações sobre as rotas e caminhos a serem percorridas, pois as geotecnologias trazem isso de forma mais precisa e de forma acessível.

\footnotetext{
${ }^{1}$ Informações retiradas do site oficial da plataforma: http://pt.wikiloc.com/
} 


\section{Contribuições da geografia e sensoriamento remoto ao turismo}

O espaço, considerado como uma das categorias de análise fundamentais para a geografia, configura-se como o principal campo de apropriação da atividade turística. Conforme menciona Resende e Xavier (2008), o turismo é uma experiência geográfica, uma vez que o mesmo se desenvolve no meio dos elementos dos espaços geográficos, com intensiva relação entre o homem e a natureza, fazendo constante uso da paisagem e da comunidade receptora como atrativo. A geografia como uma das ciências que tem realizado trabalhos acerca do planejamento territorial urbano, tem contribuído para a organização territorial levando em consideração as características físicas e sociais do espaço.

O uso do sensoriamento remoto como ferramenta auxiliar ao planejamento urbano, - e desta forma ao turismo através do estudo de unidades de paisagem é uma metodologia que permite levantar os aspectos característicos da região através da estratificação do espaço geográfico, dedicando a partir dos aspectos físicos e de uso atual do solo áreas para agricultura, ocupação urbana e dentre outros para a prática do turismo (FARIA; PADOAN, 2015). Este modelo de planejamento urbano pode ser pensado como uma primeira aproximação do planejamento do turismo no espaço, pois trará informações que sustentarão as análises posteriores em uma escala mais aproximada do local de estudo. Este e outros modelos de análise espacial que visam o planejamento urbano não são suficientes para o planejamento do turismo de maneira sistemática e que englobe os aspectos fundamentais na escala local, sendo necessário um estudo dedicado a tal fim de maneira complementar.

Outros trabalhos como o de Freitas (2006) já mostraram que a geografia pode contribuir para o planejamento do turismo, uma vez que é uma ciência que permite através de suas técnicas e análises - como o sensoriamento remoto - uma visão ampla e integrada de todos os aspectos relevantes para o turismo. O trabalho de Freitas (2006) ressalta a eficácia do geoprocessamento como ferramenta de estudo e pesquisa na área do turismo. O SIG e seus métodos e técnicas podem ser utilizados de maneira que permitam a simulação e representação do espaço real e seus elementos atuantes (FREITAS, 2006). A geografia, assim, passa a ser uma ciência aliada do turismólogo ou gestor não apenas no uso das técnicas de sensoriamento remoto, como também na avaliação do espaço geográfico.

\subsection{Sensoriamento Remoto no Parque Nacional da Serra Do Cipó}

O Parque Nacional da Serra do Cipó já é um espaço consolidado no que se refere as atividades turísticas e a atratividade do local pelas pessoas de todo o estado de Minas Gerais. Porém, o planejamento do turismo é algo que no Brasil ainda é muito recente e é uma busca inesgotável, visando o melhor aproveitamento da área para a atividade, uma vez que, um planejamento bem feito do turismo é algo que pode trazer bons recursos financeiros para os municípios em que não se faz presente outros recursos.

Segundo Câmara (2002), a ênfase da análise espacial é "mensurar propriedades e relacionamentos, levando em conta a localização espacial do fenômeno em estudo". Neste sentido, o presente estudo buscou no Parque Nacional da Serra do Cipó mensurar as propriedades físicas do parque, com o uso do Sensoriamento remoto, levantando informações que podem subsidiar o planejamento do turismo na área, ou mesmo, que sirva de modelo para ser aplicado em outras áreas de potencial turístico.

\subsection{Dados disponibilizados}

Conforme dito anteriormente, há uma grande variedade de dados disponibilizados na internet acerca de informações georreferenciadas acerca do turismo. A figura 2 é um mapa do PARNA Cipó, cujas informações contidas nele foram retiradas da plataforma - já mencionada - Open Street Map. 


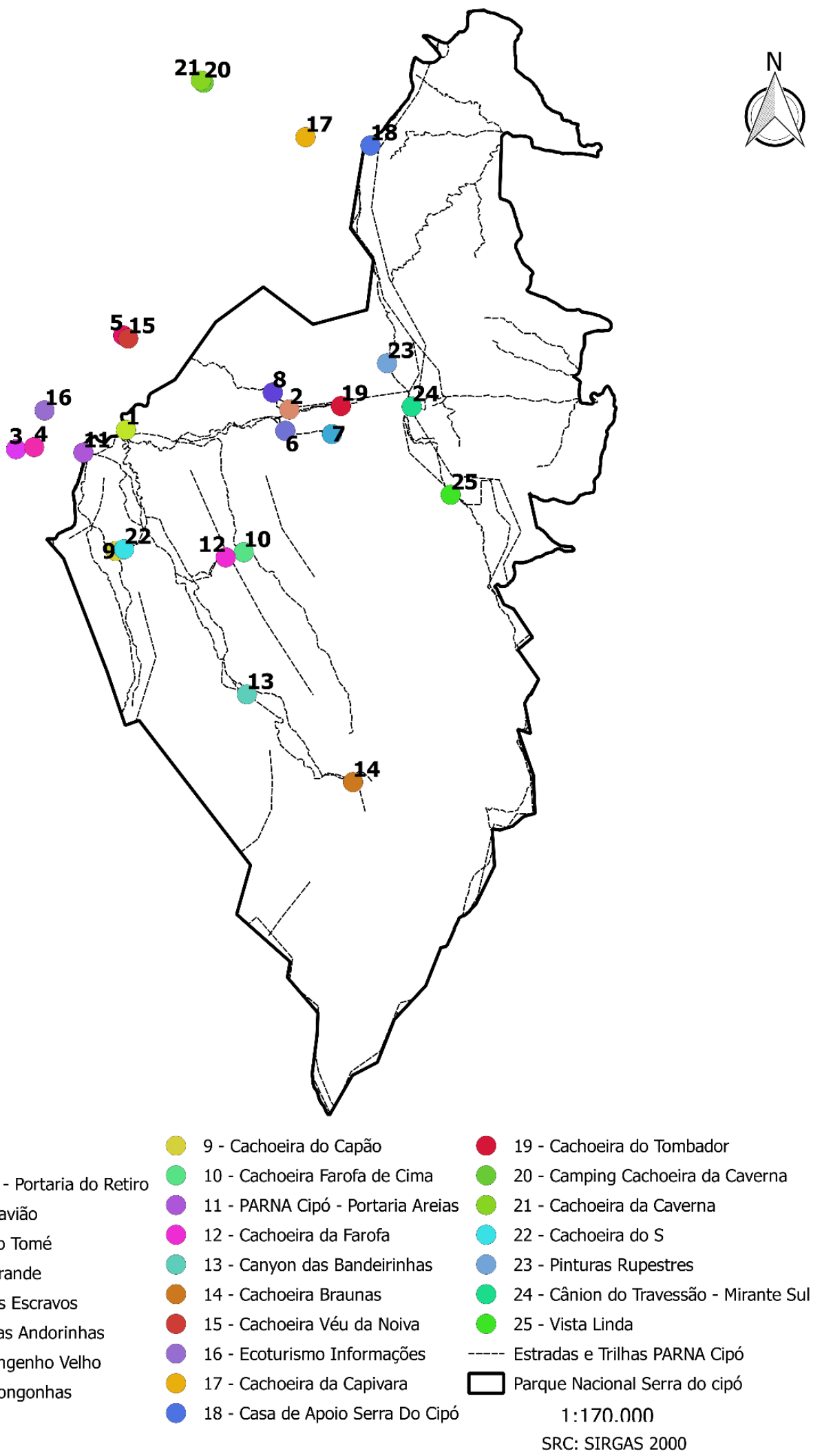

Figura 2 - Mapa das localizações dos principais pontos do PARNA Cipó e seu entorno e as trilhas e caminhos pertencentes ao parque. Fonte: Elaboração própria 
Um dos primeiros desafios para o planejador do turismo é a aquisição e obtenção de dados referente a área em que se planeja atuar. A necessidade em compreender o espaço turístico requer, primeiramente, a construção de uma base de dados que permita a compreensão desta organização.

A figura 2 é o ponto de partida para o planejamento do turismo, uma vez que sem ir ao campo ainda para validação das informações, os usuários que se aventuraram em ir ao local já mapearam os pontos de interesse turísticos. Conforme se observa na figura 2, as trilhas, cachoeiras e atrações turísticas, não só dentro do parque, mas também ao seu entorno, já estão mapeadas, o que nos fornece, antes de qualquer coisa, uma visão espacial da área de estudo.

A plataforma Open Street Map, na qual foram retiradas as informações que compõem a figura 2, disponibiliza outras informações de interesse ao profissional que pretende planejar o turismo e ao próprio turista, como restaurantes, cafés, bancos, dentre outros. Apesar da precisão das informações serem confiáveis, é importante ressaltar a importância da validação das informações em campo, para correção de possíveis imprecisões decorrentes do mapeamento colaborativo.

Uma vez que a figura 2 está disponível para o profissional da área em que se pretende realizar o planejamento do turismo, a dimensão da estrutura e de organização administrativa parte-se agora para a construção da base de dados acerca da superfície contínua da área.

\subsection{Hipsometria}

O mapa de hipsometria, representado na figura 3, auxiliará o profissional a mensurar o grau de dificuldade e periculosidade de vários aspectos, como por exemplo, a construção e gestão de trilhas ecológicas, bem como também, identificar possíveis pontos para a prática de esportes como montanhismo, escalada.

A declividade em boa parte no interior do PARNA Cipó é suave e em alguns pontos escarpados. Quando é feita a sobreposição das linhas que representam as trilhas, percebe-se que os caminhos são fáceis, partindo do ponto de vista de que, apesar de longos, são em sua maioria planos.

As partes escarpadas do relevo são as áreas em que se encontram as cachoeiras e quedas d'águas, onde se fazem presentes as mais famosas atrações do parque, como a cachoeira das Andorinhas e a cachoeira da Farofa. O mapa hipsométrico mostra-se bastante útil quando deseja-se encontrar possíveis locais para "exploração" de cachoeiras, sendo possível identificar áreas em que elas se encontram e traçar os melhores caminhos para que se chegue até elas.

A hipsometria, representada na figura 3, mostra que a maior parte do PARNA Cipó se encontra em uma altitude de 1319 metros, sendo poucas áreas com 1149 metros e apenas uma faixa central com uma altitude entre 638 e 809 metros. Estas informações referentes à hipsometria e declividade são importantes para definição do grau de dificuldade para os turistas e informação aos mesmos, sobre a distância a ser percorrida e quantos metros terão de subir. O PARNA Cipó tem todas estas informações disponíveis na entrada do parque, mas, para áreas em que se pretende fazer um planejamento pioneiro do turismo, o estudo do grau de dificuldade e acesso aos pontos de lazer por meio das informações de hipsometria e declividade pode ser útil. 


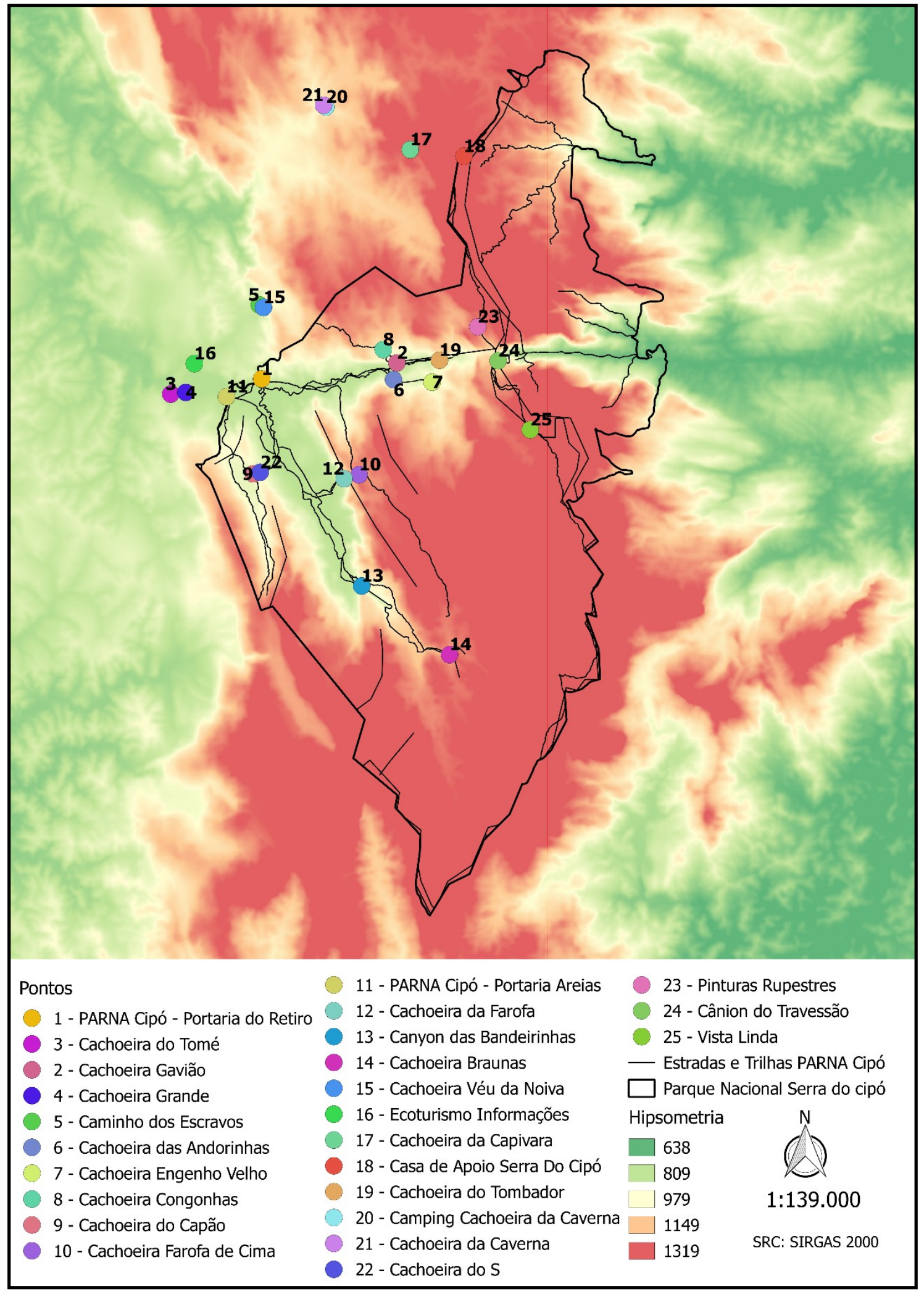

Figura 3 - Mapa das localizações dos principais pontos do PARNA Cipó e seu entorno e as trilhas e caminhos pertencentes ao parque e a hipsometria do relevo. Fonte: Elaboração própria, a partir dos dados Topodata INPE (2009). 
Apesar do relevo escarpado e grandes amplitudes altimétricas, percebeu-se em campo que uma vez que você chega na parte mais alta do parque, as trilhas são retilíneas, passando por uma suave ondulação em alguns trechos. Mesmo que a maior parte do parque se encontre em cotas altimétricas altas, as trilhas são fáceis de serem realizadas, não apresentando grandes subidas e descidas. As trilhas foram elaboradas, sendo que, em algumas partes teve-se a impressão de que houve o uso de maquinário para abertura do caminho, uma vez que em alguns trechos são largos como uma estrada de terra comum.

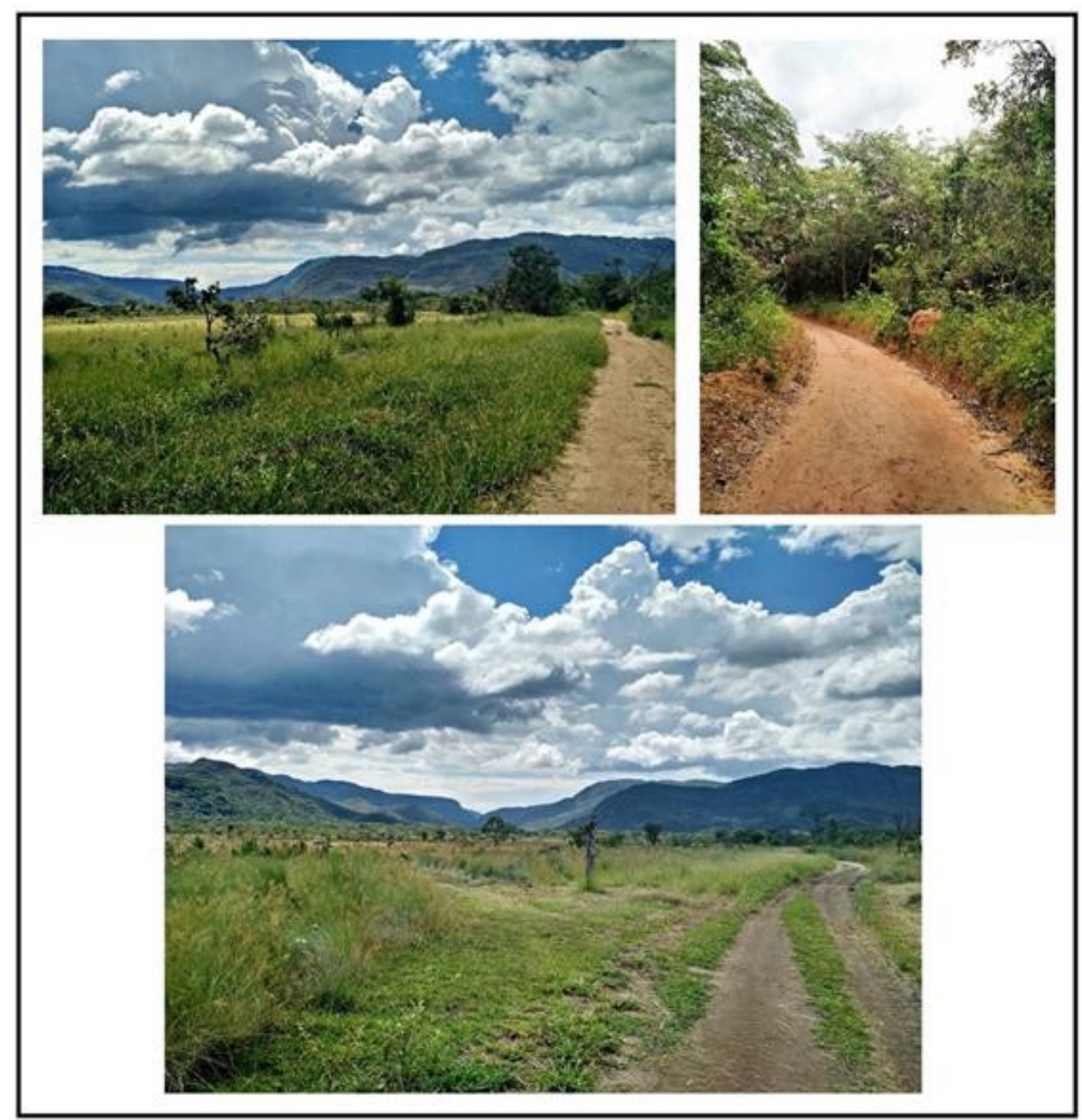

Figura 4 - Fotos da trilha ao longo do PARNA Cipó. Fonte: Acervo próprio 
Estes aspectos mencionados na figura 4 permitem às pessoas envolvidas no planejamento do turismo mensurarem como será feita a abertura de trilhas e caminhos para uma prática segura da atividade turística. Uma vez que se tem a disponibilidade de uma carta que permite averiguar todo o relevo e declividade da área, é possível, também, analisar a viabilidade de máquinas ou mesmo recursos humanos para o trabalho de infraestrutura da área.

\subsection{Vegetação}

Muitas vezes é inevitável que a prática do turismo não acarrete na ação antrópica do meio ambiente, resultando em casos mais graves, como as queimadas por exemplo. Não só o PARNA Cipó, mas, diversos outros parques nacionais brasileiros têm em sua história um infeliz histórico de queimadas, decorrente das mais diversas causas, sendo a mais comum as provenientes de atividades pastoreias ao redor do parque. $\mathrm{O}$ sensoriamento remoto, neste caso, com o uso do mapa NDVI, pode auxiliar no monitoramento da vegetação do parque através da combinação de bandas de satélite.

A figura 5 é a representação da vegetação na área de estudo, através do processamento das bandas 4-5 do satélite Landsat- 8 com tratamento dos sensores NDVI. O índice NDVI apresenta valores que variam de -0.042000 até 0.480000 sendo representados em uma escala de cores que variam do vermelho (água), passando pelo laranja (solo exposto, ou vegetação rasteira) até o verde escuro (vegetação densa).

Conforme mostra a figura 5, no interior do PARNA Cipó, não se percebe grandes áreas de vegetação densa, sendo presente em sua maior área vegetação de relva baixa. Na parte nordeste, e sudeste fora dos limites do PARNA Cipó são onde se evidencia maior presença de vegetação densa. Fora destas regiões apenas algumas pequenas áreas esparsas percebem-se áreas mais verdes no mapa, que expressam no índice NDVI vegetação densa. Algumas áreas expressas pela cor vermelha escuro representam solo exposto ou corpos d'água, sendo mais marcante na parte sudoeste e norte do parque.

O mapa NDVI permite ao gestor do parque, ou o órgão público, avaliar em uma escala temporal os danos causados à natureza pelo turismo, uma vez que, o mapa permite a identificação de áreas que antes eram vegetação e passaram a ser solo exposto. Mesmo que a atividade turística respeite as normas e condutas do PARNA Cipó, e a ação antrópica resulte em um impacto imperceptível na imagem de satélite, é importante o monitoramento ambiental de transformação da vegetação. O mapa NDVI permite também que o gestor verifique a variação da vegetação decorrente das mudanças de estações do ano e variações climáticas nos períodos de seca e chuva e, quando necessário, suspender as atividades turísticas em áreas suscetíveis a queimadas.

A figura 6 demonstra fotografias tiradas ao longo das trilhas percorridas no PARNA Cipó, e servem para demonstrar a preservação da mata, mesmo com intensa visitação turística. As áreas em que se evidencia a ação antrópica proveniente do turismo, se limitam às trilhas e estradas demarcadas pelos gestores do parque. 


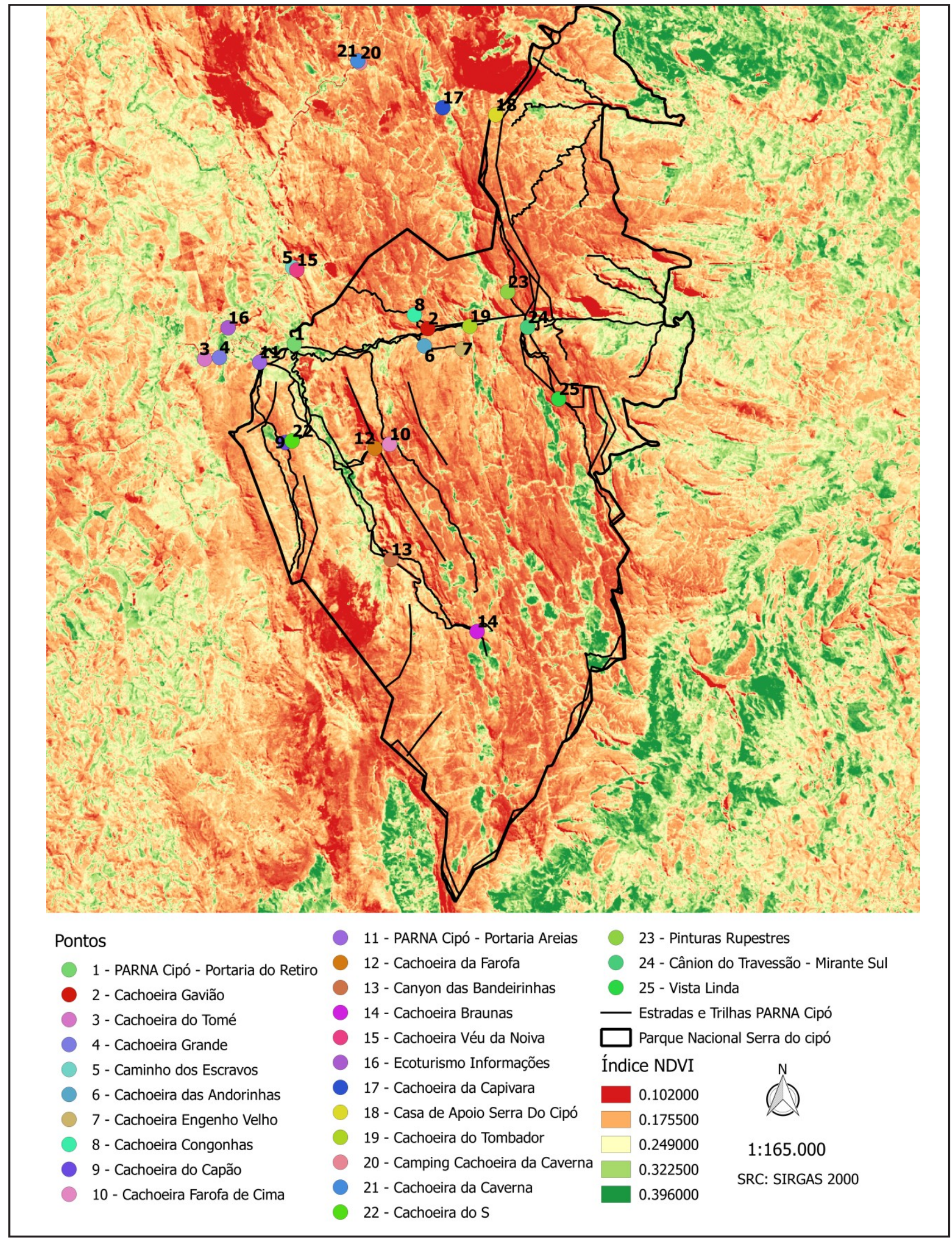

Figura 5 - Mapa das localizações dos principais pontos do PARNA Cipó e seu entorno e as trilhas e caminhos pertencentes ao parque e vegetação expresso pelo Índice NDVI. Fonte: Elaboração própria, a partir das bandas 4 e 5 do satélite Landsat-8. 


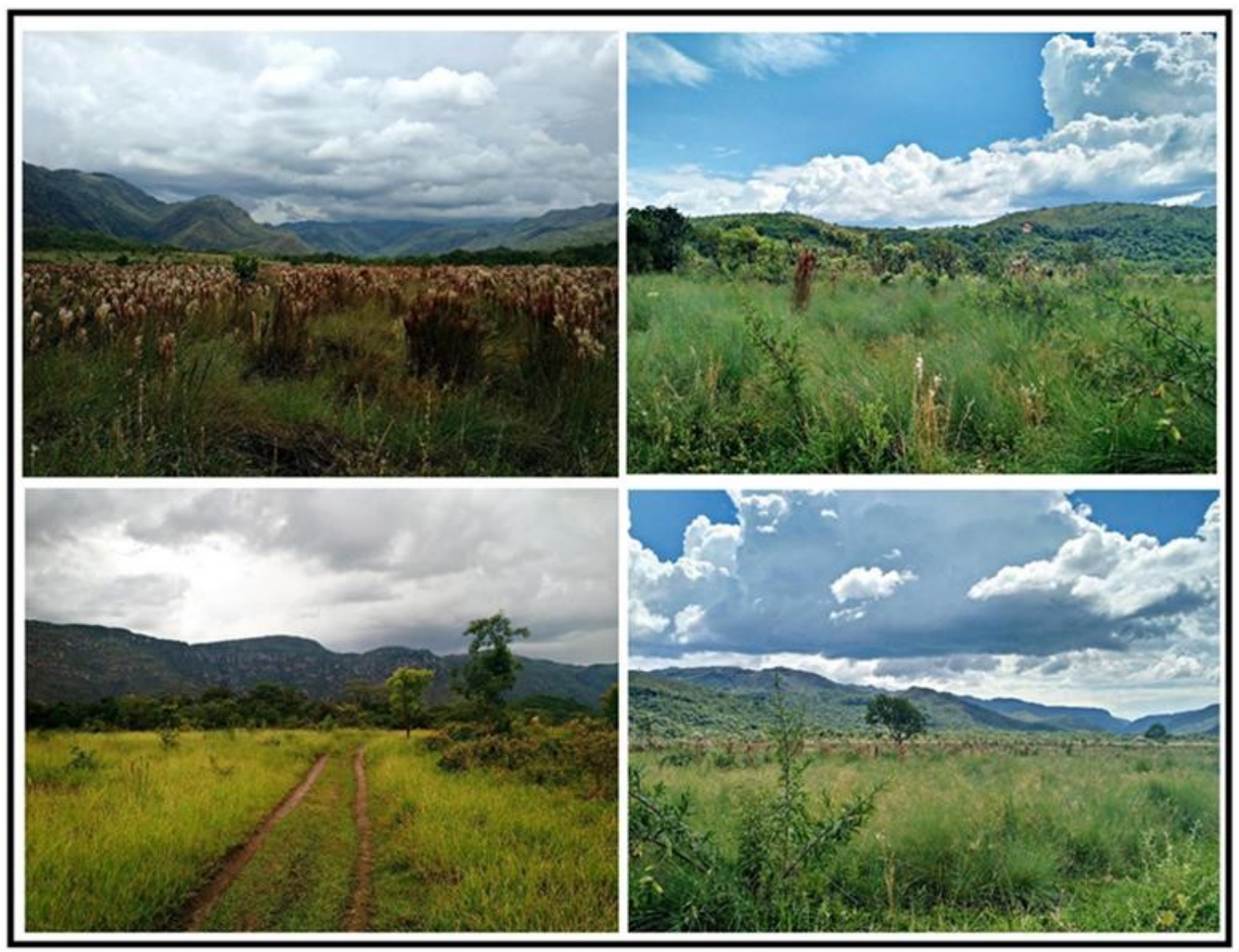

Figura 6 - Fotos da vegetação ao longo das trilhas do PARNA Cipó. Fonte: Acervo Próprio.

\section{Considerações}

O turismo sendo uma área de conhecimento interdisciplinar, tem a geografia como uma das ciências fundamentais para compreender o fenômeno turístico, uma vez que a mesma se dedica ao estudo dos processos de produção e reprodução do espaço, bem como sua organização e aproveitamento de suas potencialidades, visando sempre o benefício dos residentes e dos turistas em determinado local.

Os métodos utilizados permitem que o turismólogo obtenha uma relativa facilidade de atualização dos dados levantados no decorrer do presente trabalho, possibilitando assim uma interpretação na relação espaço/tempo e as transformações que dela ocorrem. Além disso, é possível que os usuários dos projetos de mapeamento colaborativo apontem novas possibilidades de atividades turísticas, até então desconhecidas oficialmente, indicando novas trilhas e caminhos para a prática de caminhadas ecológicas, por exemplo.

Por mais que muitos agentes atuem na transformação da natureza e na geografia do ambiente visando o exercício do turismo, o Estado é o principal responsável pelo planejamento territorial. Nesse sentido, a utilização do sensoriamento remoto permite-o uma visão ampla do planejamento realizado e a manutenção das políticas adotadas dentro do território. Além da importância para o planejamento, o sensoriamento remoto pode fornecer maior dinamismo 
ao turismo no Brasil, pois propicia a integração com outras tecnologias que vêm se consolidando no uso cotidiano brasileiro.

O sensoriamento remoto como ferramenta de análise espacial não deve ser confundido como um substituto aos modelos empregados pelos turismólogos, que visam o trabalho de campo e a imersão local como elementos indispensáveis para estudos relativos ao espaço social. A presença do profissional é importante para que seja possível perceber aspectos importantes da sociedade e também das características físicas do lugar, estes que o sensoriamento remoto, por alguma limitação, possa não ter identificado.

A metodologia empregada no presente estudo não esgota a discussão acerca dos modelos de planejamento espacial do turismo, mas reforça que a integração entre ciências e metodologias aplicáveis podem ser úteis no que se refere à busca do melhor resultado. É importante que futuros trabalhos acerca do tema busquem aprimorar os métodos e modelos de planejamento e análise espacial do turismo integrando as novas tecnologias SIG e uma visão socioespacial do turismo.

\section{Referências}

CÂMARA, Gilberto et al. Análise espacial e geoprocessamento. Análise espacial de dados geográficos, v. $2,2002$.

FARIA, Erick de Oliveira; PADOAN, Lucas de Lima Fernandes. Planejamento territorial ambiental do município de Arcos (MG) por unidades de paisagem. Revista Eletrônica em Gestão, Educação e Tecnologia Ambiental (Fechada para submissões por tempo indeterminado), v. 19, n. 3, p. 433-440, 2015.

FREITAS, Christian Rezende. Impacto das novas técnicas de geoinformação nos estudos espaciais e nas representações cartográficas destinados ao turismo. 2006. Tese de Doutorado. Dissertação (Mestrado)-Universidade Federal de Minas Gerais, Instituto de Geociências, Belo Horizonte.

Instituto Chico Mendes de Conservação - ICMBIO. Relatório Final: Plano de Manejo do Parque Nacional da Serra do Cipó e da APA Morro da Pedreira. Cardeal Mota, 2007. Disponível em: $<$ http://www.icmbio.gov.br/portal/images/stories/docs-planos-de-

manejo/parna_serra_do_cipo_pm_rel_e_planej.pdf>. Acesso em: 03 ago. 2016.

RESENDE, Letícia Antunes; XAVIER, Herbe. As contribuições das geotecnologias à atividade turística. Caderno de Geografia, v. 18, n. 29, p. 137-144, 2008.

STEINKE, Valdir Adilson; SILVA, Gustavo Bayma Siqueira da. Distribuição espacial de serviços turísticos com base em sistemas de informações geográficas-SIG’s no plano piloto de Brasília (DF). 2005.

VALERIANO, Márcio de Morisson. Visualização de imagens topográficas. Anais do XIII SBSR-Simpósio Brasileiro de Sensoriamento Remoto, Florianópolis-SC, Brasil, p. 21-26, 2007. 